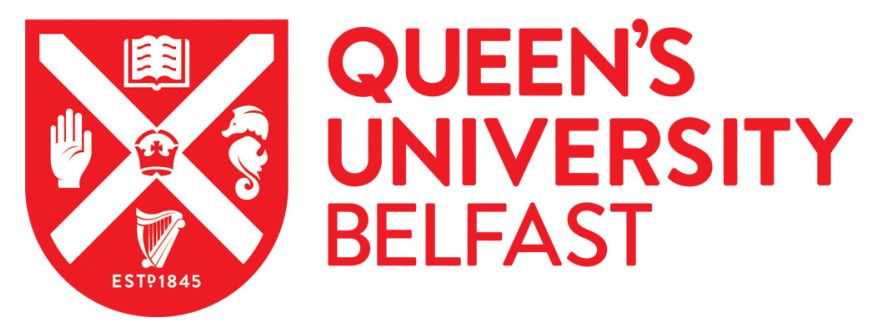

\title{
Risk of Type 1 Diabetes in the Offspring Born through Elective or Non- elective Caesarean Section in Comparison to Vaginal Delivery: a Meta-Analysis of Observational Studies
}

Tanoey, J., Gulati, A., Patterson, C., \& Becher, H. (2019). Risk of Type 1 Diabetes in the Offspring Born through Elective or Non-elective Caesarean Section in Comparison to Vaginal Delivery: a Meta-Analysis of

Observational Studies. Current Diabetes Reports, 19, [124]. https://doi.org/10.1007/s11892-019-1253-z

Published in:

Current Diabetes Reports

Document Version:

Peer reviewed version

Queen's University Belfast - Research Portal:

Link to publication record in Queen's University Belfast Research Portal

Publisher rights

() 2019 Springer Science+Business Media, LLC, part of Springer Nature.

This work is made available online in accordance with the publisher's policies. Please refer to any applicable terms of use of the publisher.

\section{General rights}

Copyright for the publications made accessible via the Queen's University Belfast Research Portal is retained by the author(s) and / or other copyright owners and it is a condition of accessing these publications that users recognise and abide by the legal requirements associated with these rights.

Take down policy

The Research Portal is Queen's institutional repository that provides access to Queen's research output. Every effort has been made to ensure that content in the Research Portal does not infringe any person's rights, or applicable UK laws. If you discover content in the

Research Portal that you believe breaches copyright or violates any law, please contact openaccess@qub.ac.uk. 


\title{
Risk of Type 1 Diabetes in the Offspring Born Through Elective or Non-elective Caesarean Section in Comparison to Vaginal Delivery: A Meta-analysis of Observational Studies
}

Justine Tanoey ${ }^{1}$, Amit Gulati ${ }^{1}$, Chris Patterson ${ }^{2}$, Heiko Becher ${ }^{1}$

\author{
Authors' affiliation: \\ ${ }^{1}$ Institute of Medical Biometry and Epidemiology, University Medical Center Hamburg- \\ Eppendorf. \\ Address: \\ Institute of Medical Biometry and Epidemiology, University Medical Center Hamburg- \\ Eppendorf. Martinistrasse 52, 20246 Hamburg, Germany. \\ ${ }^{2}$ Centre for Public Health, Queen's University of Belfast, Northern Ireland. \\ Address: \\ Centre for Public Health, Queen's University Belfast. \\ Grosvenor Road, Belfast BT12 6BJ, United Kingdom.
}

\section{Corresponding author:}

Justine Tanoey

Address:

Institute of Medical Biometry and Epidemiology, University Medical Center HamburgEppendorf. Martinistrasse 52, 20246 Hamburg, Germany.

Phone: 0049-40-7410-53609. Email: j.tanoey@uke.de.

\section{Co-author emails:}

\author{
a.gulati@uke.de \\ C.Patterson@qub.ac.uk \\ h.becher@uke.de
}

\section{Abstract}

Background: Caesarean section (CS) has been associated with an increased risk of Type 1 Diabetes (T1D). The lack of exposure to maternal vaginal and anal microbiome and bypassing the labor process often observed in elective CS may affect neonatal immune system development. This study aims to summarize the effects of elective and non-elective CS on T1D risk in the offspring.

Methods: A systematic literature search was conducted online for publications providing data on elective and non-elective CS with T1D diagnosis in children and young adults, followed by a 
meta-analysis from selected studies. Newcastle-Ottawa Scale and GRADEpro tool were applied for quality analysis.

Results: Nine observational studies comprising over 5 million individuals fulfilled the inclusion criteria. Crude OR estimates showed a $12 \%$ increased T1D risk from elective CS compared to vaginal delivery with significant heterogeneity. Adjusted ORs from seven studies did not show T1D risk differences from either CS category, and heterogeneity was detected between studies. Separate analysis of cohort and case-control studies reduced the heterogeneity and revealed a slight increase in T1D risk associated with elective CS in cohort studies (adjusted OR $=1.12(1.01-1.24))$, and a higher increased risk associated with non-elective CS in casecontrol studies (adjusted OR $=1.19(1.06-1.34)$ ).

Conclusion: Summarized crude risk estimates showed a small increased T1D risk in children and young adults born through elective CS compared to vaginal delivery, but with significant heterogeneity. Adjusted risk estimates by study design indicated a slightly increased T1D risks associated with elective or non-elective CS.

Keywords: Autoimmune disease, Caesarean section, Elective Caesarean section, Meta-analysis, Type 1 Diabetes.

\section{Introduction}

Risks and benefits of Caesarean section (CS) have never been more relevant as worldwide CS rates are at their highest [1]. Between 1990 and 2014 the estimated global average rates from 121 countries have climbed from $6.7 \%$ to $19.1 \%$, with Europe experiencing a $13.8 \%$ increase to $25 \%$ and Northern America a $10 \%$ increase to $32.3 \%$. This trend is expected to continue, especially in middle and high-income countries [1].

CS is associated with short and long-term risks for the child [2]. The procedure has been associated with higher risks of diseases related to the offspring's immune system, namely asthma and Type 1 Diabetes (T1D) [3-5, 2, 6]. Type 1 Diabetes incidence in children under 15 years old are increasing in most parts of the world, and rates are particularly high in several European and North American countries, as well as Australia [7]. In Europe the incidence is estimated at 15,000 in 2005 and projected to increase more than $60 \%$ to over 24,000 cases by 
2020 [8]. A recent study on incidence rates from 1989 to 2013 at multiple centres in 22

European countries showed no clear indication of the rates slowing down in the majority of these countries [9]. The incidence rate in young adults and adults are lower but may be rising as well [10]. The disease results from autoimmune-destruction of pancreatic beta cells leading to inadequate insulin production. The disease can manifest at any age, but new diagnoses seem to peak in early adolescence [7]. A meta-analysis published in 2008 of more than 2 million CS-born children linked CS to an approximately 20\% higher risk of developing T1D, after adjustment of maternal diabetes history and other possible confounders [4].

Bypassing the birth canal in CS is thought to reduce exposure to the mother's vaginal and anal microbiome, which may result in subsequent suboptimal development of the child's immune system. The so-called "hygiene hypothesis" proposes that certain microbiome colonization is necessary for healthy immune system maturation, and the lack of its diversity and numbers have been associated with the development of immune disorders including T1D [11-15]. Studies have described the different microbiome colonization apparent in children born through CS compared to vaginal delivery $[16,11]$ and children with or without T1D [17]. Observed rising autoimmune disease frequencies, including T1D, and lower infection rates due to more hygienic living environment support the hypothesis [18].

Another difference between vaginal delivery (VD) and CS that may also contribute to developing T1D is the possibility to bypass "labor". This process is responsible for the HPA (Hypothalamic Pituitary Axis) activation, which initiates a cascade of reactions resulting from "labor stress" that prepares the neonate to adapt to its new environment outside the mother [19]. Omission of this process could be followed by delayed risks of immune development impairments $[14,20]$. As more women deliver by CS even without medical indication, as reported in a U.S. study [21], the potential disadvantage of pre-labor birth becomes 
increasingly pertinent. Moreover, it is possible that both theories describe mechanisms through which elective CS, in particular, may contribute to the development of T1D [14, 22].

Extensive studies relating CS to T1D have been published, but in contrast to the previous metaanalysis [4], we focus particularly on studies that distinguish between the different types of CS. This paper aims to systematically review studies that highlight elective (planned) and nonelective CS associated with T1D development in children and young adults and produce a risk estimate from each procedure compared to vaginal delivery. It also provides an analysis of the association between CS, in general, as compared with VD and T1D risk from the selected studies.

\section{Methods}

Search strategy and study selection

A systematic search strategy was developed following the PICO (Patient, Intervention, Comparison, Outcome) framework. Applied search terms were (((birth OR delivery $O R$ caesarean OR cesarean OR labor)) AND (child OR offspring OR adolescent OR young adult)) AND (Type 1 Diabetes OR IDDM OR T1D) with limits to humans. The searches were conducted on MEDLINE, Web of Science and CINAHL (The Cumulative Index to Nursing and Allied Health Literature) databases for articles published before $23^{\text {rd }}$ April 2018. Duplicates were removed prior to screening articles by their title or abstract. These articles were then subject to full-text screening for eligibility. This search and study selection process were performed by two independent reviewers (JT and $\mathrm{AG}$ ) and any discordance resolved by discussion with a third reviewer (HB).

Eligibility and exclusion criteria 
Original studies that reported effect sizes or adequate data for calculation of T1D risk in children or young adults associated with elective CS and non-elective CS on were included. Diagnosis was restricted up to the age of 24 years, applying the "young adult" definition by the World Health Organization [23]. When studies indicated availability of data, authors were contacted to provide additional effect size estimates. Studies which only reported CS without specifying whether elective or non-elective (emergency) were excluded.

\section{Data extraction and statistical analysis}

Data extraction included the number of children born by each mode of delivery, the number of cases and controls from case-control studies or the number of children who were and were not diagnosed with T1D by the end of the study period from cohort studies, and confounding variables. These study characteristics were then presented in a table. Available adjusted hazard ratios (HR), risk ratios (RR) and odds ratios (OR), as well as, the adjusted confounders were either extracted from the papers, or calculated when the data were available (using the Mantel-Haenszel method), or gathered from contacted authors. As T1D is considered a rare disease, proportional HR, RR and OR are treated similarly [24] and presented as OR.

Summary crude OR for risk of CS compared to VD on T1D were estimated by combining data from the previous meta-analysis [4] and more studies identified in this review. Similar studies were only included once for the overall effect estimate. Risk of T1D estimates associated with elective CS compared to VD and emergency CS compared to VD were calculated only from studies eligible for this review. In addition, elective CS with non-elective CS were also briefly compared.

Number of cases and non-cases in each mode of delivery were applied in the pooled crude OR estimates. Adjusted ORs and corresponding standard errors (SE) calculated from the $95 \%$ confidence interval $(\mathrm{Cl})$ were applied in the pooled adjusted effect size estimates (aOR). 
Inverse weighted meta-analysis using a random effects model for binary data was performed to estimate pooled effect sizes. Heterogeneity estimates, $I^{2}$, indicate how much variability in the estimates is due to heterogeneity, and $\tau^{2}$ (investigated with DerSimonian and Laird method) indicates the total amount of heterogeneity $[25,26]$. Funnel plots were generated to check for publication bias. Subgroup analyses divided the studies into cohort and case-control studies were performed to identify whether the difference in study design is caused by the different study designs. All statistical analyses were performed with R software (version 3.3.2). Estimates are considered significant when $p$ value is $<0.05$.

\section{Study and evidence quality assessment}

Individual study quality was determined using the Newcastle-Ottawa Scale (NOS) for observational studies [27]. The overall quality of evidence was assessed using the GRADE guidelines [28-30].

\section{Results}

Systematic literature search

Literature database search yielded 4,376 publications, including review articles and meeting proceedings. After deduplication, we screened the titles and abstracts and removed 3,481 articles. The full texts of the 104 remaining articles were appraised following the inclusion criteria. Eighty-nine articles did not report data separating elective and non-elective CS, two reported part of or the same studies, and one reported a population within a geographical scope and time period of a larger study. One study was excluded as it investigated only children with high-risk HLA genotype, leaving eleven studies to be potentially included in our meta-analysis. 
Four of the eleven studies only presented crude effect sizes and one reported an adjusted effect estimate for elective CS and VD but not for non-elective CS and VD. Adjusted effect sizes for both types of CS and VD were reported in three studies. In one study sufficient information about maternal diabetes enabled a calculation of effect size adjusted for that variable using the Mantel-Haenszel method. Authors of six articles were contacted for unreported adjusted effect sizes, another one for data on elective and non-elective CS. Three responded with the necessary information, while the latter was unable to provide the data. One author did not respond to a request to clarify their definition of primary CS regarding electiveness, and the article was excluded. Finally, nine studies were included in the quality and meta-analysis. The selection process is illustrated in ESM_Figure 1_Study selection.

\section{Study characteristics}

There were nine observational studies, five cohort and four case-control studies, included in this analysis. Eight were conducted in Europe and one in Australia. Most studies ascertained cases from regional or national patient registries, and one used hospitalization records. Two studies from Scotland have a short overlapping time period in one region (Patterson, et al [31] and Robertson, et al [32]), and two studies from Sweden also utilised data from an overlapping time period but in different study designs (Khashan, et al [33] and Samuelsson, et al [34]). The age of diagnosis differs between studies, with one cohort study following children from birth until the age of 5- 6 years, while others defined their cases until age 15, 18 and the oldest at 27 years old.

Having extracted their data from official registries, most cohort studies are able to adjust for some confounding variables deemed relevant to T1D risk. Maternal diabetes is a common confounding variable, as well as gestational age and birth weight. One study also considered paternal age and history of diabetes. Another study presented an analysis which includes CS 
and T1D data in siblings to adjust effect estimates. Relevant study characteristics are presented in Table 1.

Meta-analysis

Before distinguishing between elective and non-elective CS we present an overall CS result. The basis for this analysis is studies from the previous meta-analysis by Cardwell et al ( 20 studies) [4], in which one of the studies distinguished between elective and emergency CS [35], while another mentioned finding a significant difference for elective CS as an additional analysis [31]. The seven later studies that made this distinction were then added. Table 2 shows a summary of crude and adjusted risk estimates between all CS and VD, elective CS and VD, non-elective CS and VD and between elective and non-elective CS from all studies. Four studies differentiated spontaneous VD with assisted or instrumental VD. For the purpose of this analysis, the records from both procedures are merged as VD in crude risk summaries, and reported adjusted risk estimates from only spontaneous VD is applied to adjusted risk summary.

A summarized crude OR for CS compared to VD on the T1D risk 27 studies showed that there was a significant increased risk (OR $1.12(1.05-1.20)$ ). However, significant heterogeneity was detected (Table 2). Analysis focused on the nine currently included studies showed an insignificant overall crude OR of $1.06(0.98-1.15)$ for CS on T1D risk with significant heterogeneity across studies. Separate analysis from cohort studies did not show any significant risk, but there was significant summary OR of $1.25(1.03-1.52)$ from case-control studies with insignificant heterogeneity.

Figure 1 shows the risk estimates for T1D in elective CS compared to VD from nine studies identified in the systematic review. A significant higher risk (OR $1.12(1.00-1.24)$ was 
estimated, with significant heterogeneity. Analysis on separate study designs did not indicate significant risk estimates from both groups, and significant heterogeneity estimates remained.

The risk of non-elective CS on T1D compared to VD (Figure 1) according to the summary crude OR was $1.05(0.89-1.24)$. Subgroup results from cohort and case-control studies showed insignificant heterogeneity within each group, but the crude ORs of $0.95(0.88-1.02)$ and 1.33 $(1.07-1.65)$, respectively, indicated a higher T1D risk posed by non-elective CS in case-control studies.

Five cohort and two case-control studies enabled estimations from adjusted ORs (aOR) of elective CS compared to VD and non-elective CS compared to VD. Adjustment variables vary between studies as presented in Table 1.

The forest plots in Figure 2 (upper plot) shows an overall aOR for elective CS on T1D risk from these seven studies was $1.09(0.97-1.22)$. Focusing on only cohort studies showed an aOR of $1.12(1.01-1.24)$ and no significant heterogeneity was found. The aOR of $1.14(0.71-1.85)$ from the case-control studies was similar in magnitude but not significant, and showed considerable heterogeneity although based on only two studies.

As for non-elective CS, the overall aOR was insignificant (Figure 2, lower plot). The cohort study summarized aOR of $1.00(0.92,1.09)$ was not significant but the case-control study aOR of 1.19 $(1.06-1.34)$ was significant with little heterogeneity observed.

\section{Publication bias analysis}

Funnel plots of studies on the risk of elective CS or non-elective CS compared to VD showed slight asymmetries, particularly for the elective CS analysis (ESM_Figure 2_Funnel plots). However, most of the studies investigated CS as one factor among others suspected to be 
associated with T1D risk, reducing the likelihood of publication bias due to positive findings. Moreover, as there are only a small number of studies, the plots are difficult to interpret and any evidence for publication bias is weak.

\section{Qualitative analysis}

Newcastle-Ottawa scales (NOS) for cohort and case-control studies were applied to determine the study quality. The cohort studies scored 7-9 out of 9, and the case-control studies scored 8-9 out of 9 indicating high quality observational studies. Detailed assessment is available as supplementary materials (ESM_Table 1). This result is summarized and applied into the GRADE risk of bias assessment as not serious.

Following the GRADE study quality assessment criteria, overall assessment of risk of bias and indirectness were not considered serious, although there were concerns about inconsistency, imprecision and publication bias. Taken together, the assessment concluded that there was very low certainty of the evidence, mainly due to high heterogeneity between the small number of studies and that the summarized ORs did not show a significant difference between delivery methods (summary of findings presented in Supplementary materials ESM Table 2).

\section{Discussion}

This systematic review found nine studies that highlighted the association between elective and non-elective CS procedures in comparison to VD and T1D risk in children and young adults. This meta-analysis includes four case-control studies with 10,925 cases of T1D and 39,543 controls in total and five cohort studies with 16,868 cases of T1D in a total cohort size of $5,261,891$ individuals. To our best knowledge, this is the first meta-analysis that assesses the risks of T1D in elective and non-elective CS compared to VD. 
Our meta-analysis of crude risk estimates found a significant increased T1D risk associated with elective CS, but there is significant heterogeneity between studies. Adjusted risk assessment of all studies did not show any significant differences in risk estimates from elective or non-elective CS compared to VD, and heterogeneity was detected. Separate analyses between study-types revealed that results from the cohort studies showed an aggregated $12 \%$ higher risk of T1D in the offspring born through elective CS compared to VD, while case-control studies showed a $19 \%$ increase in the risk in the offspring born through nonelective CS. Heterogeneity within these subgroups were insignificant.

The findings in this study adds to the knowledge gained in a previous meta-analysis where a $20 \%$ increase of T1D risk due to CS was estimated [4]. The excess risk estimate from nine studies (unadjusted) and from five cohort studies (adjusted) in this meta-analysis are in line with a hypothesis first advanced in the study by Patterson, et al, which was also included in the previous meta-analysis but was not further investigated [31]. A higher risk from elective CS compared to VD on T1D risk in the offspring supports both the hygiene and labor-stress theories, although the exact mechanisms of the causal pathways are still unclear [20]. Moreover, elective CS is often performed in the early term period and this may expose the offspring to premature birth. One study found reduced T1D risk with each additional week after 39 weeks of gestation [36]. Another study found that early-term deliveries (gestational week 37 to $38+6$ days) increases the risk of T1D diagnosed at age 5-18 years by approximately $50 \%$. The study stipulated that the "lost" days put the newborns at a similar risk as the preterm births [37]. Moreover, aberrant immune cell maturity have been observed in premature children born through pre-labor CS [38].

All the publications in this meta-analysis are regarded as high-quality observational studies (scoring 7-9 out of 9), as determined by our application of NOS. However, the scales have been 
criticised due to varied inter-rater reliability [39]. In our case, we found a relatively homogeneous quality of all studies included in our meta-analysis, so the judgement did not affect the final results. We believe the scale has some benefit despite its limitations; therefore, we decided to use it. In addition, the GRADE tool provided an additional assessment to evidence quality from the collected studies. The assessment resulted in "low quality of evidence" grade since only observational studies are included. Significant heterogeneity was also observed but this was reduced after subgroup analyses. Therefore, the discordance in which category of CS is associated with increased risk of T1D (elective CS in the cohort studies and non-elective CS in the case-control studies) is not likely explained by the study design. All adjusted risk estimates controlled for maternal diabetes, which is a known major risk factor in T1D. However, there are other potentially important covariates not available in the selfcalculated adjusted risk estimate from the Samuelsson, et al [34] case-control study, such as maternal age, birth weight and gestational age.

Without having similarly-adjusted estimates across all studies, the possibility that adjustments might affect the slight increased risks from both types of CS seen in this meta-analysis cannot be ruled out. Paternal diabetes is a known covariate for T1D in the offspring $[40,41]$. One of the studies in this analysis also found higher T1D risk associated with paternal history of the disease in their multivariate model analysis [42]. Another potentially important covariate that was not available in most studies here is paternal age. A large study in Northern Ireland found an approximately 50\% increase of T1D can be contributed to fathers aging $>35$ years [36]. Maternal BMI was also not commonly adjusted for in these studies although there is evidence that high maternal BMI in the first trimester increased T1D risk by $20-48 \%$ independent of parental diabetes [43]. 
Birth weight for gestational age, instead of birth weight and gestational age separately, may be a better adjustment variable as it considers maturity rather than growth alone, as small-forgestational-age is found to be a protective factor for T1D [44]. Admittedly, adjustment of both birthweight and gestational age may act as sufficient substitutes. Higher birth order (second or later) seem to have a protective effect, particularly in early onset T1D ( $<5$ years old) [45]. Among the studies in this systematic review, two included being first born or later in their analysis [42, 33]. Adjusting analysis with data on siblings born by a different delivery mode and did not develop T1D may also be a useful approach to control for unmeasured familial traits such as shared genes and lifestyle. Khashan, et al found that elective CS slightly increases T1D after adjusting for confounders such as maternal diabetes, maternal age, and gestational age, but controlling for siblings eliminated the significance of the previous finding, suggesting that unspecified familial traits accounted for the association [33].

\section{Limitations}

Studies included in this analysis are from developed countries in Europe and Australia. All efforts have been made to identify and include all relevant studies, but relatively few studies met the selection criteria. Data unavailability on specific types of delivery mode may be a reason for lack of reports from other countries.

Four of the studies in two countries utilized data from registers that might overlap with each other in certain time periods. However, each pair was either a cohort or case-control study, and separating the study types reduced the possibility of an exaggerated association.

Moreover, the case-control study of the pair did not provide any adjusted effect estimate, and is excluded from the adjusted risk calculation.

An attempt to isolate the presence of labor by way of comparing CS with or without labor was inconclusive due to insufficient information. Only two studies reported crude risk estimates 
from in-labor CS [44, 42]. Moreover, the non-elective CS data presented in the studies were not always categorized as in-labor CS, and the traditional classification of all unscheduled CS as emergency CS does not necessarily indicate failed labor $[46,47]$.

It should be emphasized that any role of CS in the development of T1D, is likely the result of a combination of genetic, prenatal, perinatal, environmental, and lifestyle factors [48]. Immune system development begins early in fetal life and may show aberrations (i.e. due to HLA class II or PTPN22 gene polymorphisms known to confer susceptibility to T1D) seen in T1D preceding any type of delivery [49]. However, interaction between CS and immune response genes IFIH1 and CD25 has also been associated with the manifestation of T1D [50]. Breastfeeding, time of introduction to cow's milk or gluten-containing-foods, and childhood infections have all been observed to influence the progression from islet antibodies to T1D [51-55, 41]. Although study results on many non-hereditary T1D risk factors remain inconsistent, further research into intrauterine and postnatal immune development is essential to confirm or refute these observations, especially regarding early onset T1D cases where it is more plausible that these factors play a role [41].

\section{Conclusion}

Despite existing theories on the roles of hygiene and labor-stress in the development of autoimmunity in T1D, few studies report elective and non-elective CS as separate risk factors. A systematic literature search identified nine studies that investigated the association of these delivery modes to T1D risk in the offspring. All studies were observational, with five cohorts having follow-up periods ranging from birth until 6 to 24 years of age, and four case-control studies that include T1D cases until 15 years of age. Summarized crude and adjusted risk estimates from all studies found an increased T1D risk associated with elective CS, but there was significant heterogeneity among studies. This was reduced after the studies were grouped 
into cohort and case-control studies, and the adjusted risk estimates indicated a slightly increased T1D risk related to elective or non-elective CS depending on the study design. Discrepancies in results from subgroup analyses may be due to the inconsistent adjustment of covariate variables between studies, except for maternal diabetes. A pooled study analysis with more studies and similarly adjusted variables may shed better light on this possibility. Until then, this meta-analysis indicated that T1D risk might be related to modes of delivery.

\section{Acknowledgments and Funding}

The authors thank Dr. Mairead Black (MRCOG, University of Aberdeen, UK) and Mr. Charles S. Algert (Royal North Shore Hospital, Sydney, Australia) for providing additional risk estimates. The authors JT and HB were supported by the German Federal Ministry of Education and Research (Grant Number 01ER1306 PERGOLA).

\section{Compliance with Ethical Standards}

\section{Conflict of Interest}

Justine Tanoey, Amit Gulati, Chris Patterson, and Heiko Becher declare that they have no conflict of interest.

\section{Human and Animal Rights and Informed Consent}

This article does not contain any studies with human or animal subjects performed by any of the authors. 


\section{References}

Publications of particular interest published recently, have been highlighted as:

- Of importance

$\bullet \bullet$ Of major importance

1. Betrán AP, Ye J, Moller A-B, Zhang J, Gülmezoglu AM, Torloni MR. The increasing trend in caesarean section rates: global, regional and national estimates: 1990-2014. PLos One. 2016;11(2):e0148343.

2. Hyde MJ, Modi N. The long-term effects of birth by caesarean section: the case for a randomised controlled trial. Early Hum Dev. 2012;88(12):943-9.

3. Thavagnanam S, Fleming J, Bromley A, Shields MD, Cardwell CR. A meta-analysis of the association between caesarean section and childhood asthma. Clin Exp Allergy. 2008;38(4):629-33.

4. Cardwell CR, Stene LC, Joner G, Cinek O, Svensson J, Goldacre MJ et al. Caesarean section is associated with an increased risk of childhood-onset type 1 diabetes mellitus: a meta-analysis of observational studies. Diabetologia. 2008;51(5):726-35.

5. Sinha A, Bewley S. The harmful consequences of prelabour caesarean section on the baby. Obstetrics, Gynaecology \& Reproductive Medicine. 2012;22(2):54-6.

6. Sevelsted A, Stokholm J, Bonnelykke K, Bisgaard H. Cesarean section and chronic immune disorders. Pediatrics. 2015;135(1):E92-E8.

7. DIAMOND PG. Incidence and trends of childhood type 1 diabetes worldwide 1990-1999. Diabet Med. 2006;23(8):857-66.

8. Patterson CC, Dahlquist GG, Gyurus E, Green A, Soltesz G. Incidence trends for childhood type 1 diabetes in Europe during 1989-2003 and predicted new cases 2005-20: a multicentre prospective registration study. Lancet. 2009;373(9680):2027-33.

9. Patterson CC, Harjutsalo V, Rosenbauer J, Neu A, Cinek O, Skrivarhaug T et al. Trends and cyclical variation in the incidence of childhood type 1 diabetes in 26 European centres in the 25 year period 1989-2013: a multicentre prospective registration study. Diabetologia. 2019;62(3):40817. doi:10.1007/s00125-018-4763-3.

10. Bruno $G$, Gruden $G$, Songini $M$. Incidence of type 1 diabetes in age groups above 15 years: facts, hypothesis and prospects for future epidemiologic research. Acta Diabetol. 2016;53(3):339-47.

11. Munyaka PM, Khafipour E, Ghia J-E. External influence of early childhood establishment of gut microbiota and subsequent health implications. Front Pediatr. 2014;2:109-.

12. Vaarala O. Gut microbiota and type 1 diabetes. Rev Diabet Stud. 2012;9(4):251-9.

13. Gulden E, Wong FS, Wen L. The gut microbiota and type 1 diabetes. Clin Immunol. 2015;159(2):143-53.

14. Dahlen HG, Downe S, Wright ML, Kennedy HP, Taylor JY. Childbirth and consequent atopic disease: emerging evidence on epigenetic effects based on the hygiene and EPIIC hypotheses. BMC Pregnancy Childbirth. 2016;16:4.

15. Gale EA. A missing link in the hygiene hypothesis? Diabetologia. 2002;45(4):588-94.

16. Penders J, Kummeling I, Thijs C. Infant antibiotic use and wheeze and asthma risk: a systematic review and meta-analysis. Eur Respir J. 2011;38(2):295-302.

17. Murri M, Leiva I, Gomez-Zumaquero JM, Tinahones FJ, Cardona F, Soriguer F et al. Gut microbiota in children with type 1 diabetes differs from that in healthy children: a case-control study. BMC Med. 2013;11:12. 
18. Bach J-F, Chatenoud L. The hygiene hypothesis: an explanation for the increased frequency of insulin-dependent diabetes. Cold Spring Harb Perspect Med. 2012;2(2):a007799.

19. Lagercrantz H. The good stress of being born. Acta Paediatr. 2016;105(12):1413-6.

20. Dahlen HG, Kennedy HP, Anderson CM, Bell AF, Clark A, Foureur M et al. The EPIIC hypothesis: intrapartum effects on the neonatal epigenome and consequent health outcomes. Med Hypotheses. 2013;80(5):656-62.

21. Menacker F, Declercq E, Macdorman MF. Cesarean delivery: background, trends, and epidemiology. Semin Perinatol. 2006;30(5):235-41.

22. • Francino MP. Birth Mode-Related Differences in Gut Microbiota Colonization and Immune System Development. Annals of Nutrition and Metabolism. 2018;73(suppl 3)(3):12-6. doi:10.1159/000490842. This article summarizes the possible pathways elective cesarean section could contribute to autoimmunity seen in type 1 diabetes.

23. Programming for adolescent health and development [database on the Internet]. World Health Organization. 1999. Available from:

http://www.who.int/maternal child adolescent/documents/trs 886/en/. Accessed: 18 Mar 2018

24. Jewell NP. Risk Comparisons. Am J Ophthalmol. 2009;148(4):484-6.

25. Higgins JPT, Green S. Cochrane Handbook for Systematic Reviews of Interventions Version 5.1.0 [Updated March 2011]. In: Higgins JPT, Green S, editors.: The Cochrane Collaboration; 2011.

26. Borenstein M, Hedges LV, Higgins JPT, Rothstein HR. Introduction to Meta-Analysis. Wiley; 2009.

27. Wells GA, Shea B, O'Connell D, Peterson J, Welch V, Losos M et al. The Newcastle-Ottawa Scale (NOS) for assessing the quality of nonrandomised studies in meta-analyses. 2011.

http://www.ohri.ca/programs/clinical epidemiology/oxford.asp.

28. Guyatt G, Oxman AD, AkI EA, Kunz R, Vist G, Brozek J et al. GRADE guidelines: 1. IntroductionGRADE evidence profiles and summary of findings tables. Journal of Clinical Epidemiology. 2011;64(4):383-94.

29. Guyatt GH, Oxman AD, Kunz R, Atkins D, Brozek J, Vist G et al. GRADE guidelines: 2. Framing the question and deciding on important outcomes. Journal of Clinical Epidemiology. 2011;64(4):395-400.

30. Balshem $H$, Helfand $M$, Schünemann $H J$, Oxman AD, Kunz R, Brozek J et al. GRADE guidelines: 3. Rating the quality of evidence. J Clin Epidemiol. 2011;64(4):401-6.

31. Patterson CC, Carson DJ, Hadden DR, Waugh NR, Cole SK. A case-control investigation of perinatal risk factors for childhood IDDM in Northern Ireland and Scotland. Diabetes Care. 1994;17(5):376-81.

32. Robertson L, Harrild K. Maternal and neonatal risk factors for childhood type 1 diabetes: a matched case-control study. BMC Public Health. 2010;10.

33. Khashan AS, Kenny LC, Lundholm C, Kearney PM, Gong T, Almqvist C. Mode of obstetrical delivery and type 1 diabetes: a sibling design study. Pediatrics. 2014;134(3):E806-E13.

34. Samuelsson U, Lindell N, Bladh M, Akesson K, Carlsson A, Josefsson A. Caesarean section per se does not increase the risk of offspring developing type 1 diabetes: a Swedish population-based study. Diabetologia. 2015;58(11):2517-24.

35. McKinney AP, Parslow R, Gurney K, Law G, Bodansky JH, Williams RDR. Antenatal risk factors for childhood diabetes mellitus: a case-control study of medical record data in Yorkshire, UK. Diabetologia. 1997;40(8):933-9.

36. Cardwell CR, Carson DJ, Patterson CC. Parental age at delivery, birth order, birth weight and gestational age are associated with the risk of childhood type 1 diabetes: a UK regional retrospective cohort study. Diabet Med. 2005;22(2):200-6.

37. Paz Levy D, Sheiner E, Wainstock T, Sergienko R, Landau D, Walfisch A. Evidence that children born at early term (37-38 6/7 weeks) are at increased risk for diabetes and obesity-related disorders. Am J Obstet Gynecol. 2017;217(5):588.e1-.e11. 
38. •Thysen AH, Larsen JM, Rasmussen MA, Stokholm J, Bønnelykke K, Bisgaard $\mathrm{H}$ et al. Prelabor cesarean section bypasses natural immune cell maturation. J Allergy Clin Immunol. 2015;136(4):1123-5.e6. This study illustrated the immune cell maturation distinction between premature elective cesarean section and vaginal delivery in humans.

39. Hartling L, Milne A, Hamm MP, Vandermeer B, Ansari M, Tsertsvadze A et al. Testing the Newcastle Ottawa Scale showed low reliability between individual reviewers. J Clin Epidemiol. 2013;66(9):982-93. doi:10.1016/j.jclinepi.2013.03.003.

40. Lee HY, Lu CL, Chen HF, Su HF, Li CY. Perinatal and childhood risk factors for early-onset type 1 diabetes: a population-based case-control study in Taiwan. Eur J Public Health. 2015;25(6):1024-9. doi:10.1093/eurpub/ckv059.

41. Stene LC, Gale EA. The prenatal environment and type 1 diabetes. Diabetologia. 2013;56(9):188897.

42. Clausen TD, Bergholt T, Eriksson F, Rasmussen S, Keiding N, Lokkegaard EC. Prelabor cesarean section and risk of childhood type 1 diabetes: a nationwide register-based cohort study. Epidemiology. 2016;27(4):547-55.

43. Hussen HI, Persson M, Moradi T. Maternal overweight and obesity are associated with increased risk of type 1 diabetes in offspring of parents without diabetes regardless of ethnicity. Diabetologia. 2015;58(7):1464-73.

44. Algert CS, McElduff A, Morris JM, Roberts CL. Perinatal risk factors for early onset of type 1 diabetes in a 2000-2005 birth cohort. Diabet Med. 2009;26(12):1193-7.

45. Cardwell CR, Stene LC, Joner G, Bulsara MK, Cinek O, Rosenbauer J et al. Birth order and childhood type 1 diabetes risk: a pooled analysis of 31 observational studies. Int J Epidemiol. 2011;40(2):363-74.

46. Lucas DN, Yentis SM, Kinsella SM, Holdcroft A, May AE, Wee M et al. Urgency of caesarean section: a new classification. J R Soc Med. 2000;93(7):346-50.

47. Torloni M, Betrán A, Souza J, Widmer M, Allen T, Gülmezoglu A et al. Classifications for cesarean section: a systematic review. PLoS One. 2011;6:e14566.

48. `Knip M, Luopajarvi K, Harkonen T. Early life origin of type 1 diabetes. Semin Immunopathol. 2017;39(6):653-67. doi:10.1007/s00281-017-0665-6. This review supports the notion that various factors in all life stages play intricate roles in the manifestation of type 1 diabetes.

49. Pugliese A. The multiple origins of Type 1 diabetes. Diabet Med. 2013;30(2):135-46. doi:10.1111/dme.12081.

50. Bonifacio E, Warncke K, Winkler C, Wallner M, Ziegler A-G. Cesarean Section and InterferonInduced Helicase Gene Polymorphisms Combine to Increase Childhood Type 1 Diabetes Risk. Diabetes. 2011;60(12):3300-6. doi:10.2337/db11-0729.

51. Lund-Blix NA, Stene LC, Rasmussen T, Torjesen PA, Andersen LF, Ronningen KS. Infant feeding in relation to islet autoimmunity and type 1 diabetes in genetically susceptible children: the MIDIA study. Diabetes Care. 2015;38(2):257-63.

52. Cardwell CR, Stene LC, Ludvigsson J, Rosenbauer J, Cinek O, Svensson J et al. Breast-feeding and childhood-onset type 1 diabetes: a pooled analysis of individual participant data from 43 observational studies. Diabetes Care. 2012;35(11):2215-25.

53. Beyerlein A, Wehweck F, Ziegler AG, Pflueger M. Respiratory infections in early life and the development of islet autoimmunity in children at increased type 1 diabetes risk: evidence from the BABYDIET study. JAMA Pediatr. 2013;167(9):800-7.

54. Ziegler AG, Schmid S, Huber D, Hummel M, Bonifacio E. Early infant feeding and risk of developing type 1 diabetes-associated autoantibodies. JAMA. 2003;290(13):1721-8. doi:10.1001/jama.290.13.1721.

55. Stene LC, Oikarinen S, Hyoty H, Barriga KJ, Norris JM, Klingensmith G et al. Enterovirus infection and progression from islet autoimmunity to type 1 diabetes: the diabetes and autoimmunity study in the young (DAISY). Diabetes. 2010;59(12):3174-80. 
56. Black M, Bhattacharya S, Philip S, Norman JE, McLernon DJ. Planned cesarean delivery at term and adverse outcomes in childhood health. JAMA. 2015;314(21):2271-9.

57. Clausen TD, Bergholt T, Eriksson F, Rasmussen S, Keiding N, Loekkegaard E. Elective cesarean section and risk of childhood type 1 diabetes - a nationwide cohort study. Diabetes. 2015;64:A446-A7.

58. Black M, Bhattacharya S, Philip S, Norman JE, McLernon DJ. Planned repeat cesarean section at term and adverse childhood health outcomes: a record-linkage study. PLoS Med. 2016;13(3):e1001973. 
Table 1. Study characteristics (continued on the next 3 pages).

\begin{tabular}{|c|c|c|c|c|c|c|c|c|c|c|}
\hline \multirow{2}{*}{$\begin{array}{l}\text { Author, } \\
\text { country \& } \\
\text { publication } \\
\text { year }\end{array}$} & \multirow{2}{*}{$\begin{array}{l}\text { Study } \\
\text { design }\end{array}$} & \multirow{2}{*}{ Case diagnosis } & \multirow{2}{*}{$\begin{array}{l}\text { Age at diagnosis; } \\
\text { birth years/ } \\
\text { length of follow-up }\end{array}$} & \multicolumn{2}{|c|}{ Vaginal Delivery } & \multicolumn{2}{|c|}{$\begin{array}{l}\text { Elective } \\
\text { C-Section }\end{array}$} & \multicolumn{2}{|c|}{$\begin{array}{l}\text { Non-Elective } \\
\text { C-Section }\end{array}$} & \multirow{2}{*}{ Adjustment variable } \\
\hline & & & & Cases & $\begin{array}{l}\text { Controls/ } \\
\text { Non-cases }\end{array}$ & Cases & $\begin{array}{l}\text { Controls/ } \\
\text { Non-cases }\end{array}$ & Cases & $\begin{array}{l}\text { Controls/ } \\
\text { Non-cases }\end{array}$ & \\
\hline $\begin{array}{l}\text { Patterson, et al, } \\
\text { UK (Scotland), } \\
1994 \text { [31] }\end{array}$ & $\mathrm{C}-\mathrm{C}$ & $\begin{array}{l}\text { Scotland hospital } \\
\text { discharge } \\
\text { database and } \\
\text { Regional Diabetes } \\
\text { registry (Scottish } \\
\text { Study Group for } \\
\text { the Care of } \\
\text { Diabetes in the } \\
\text { Young) }\end{array}$ & $\begin{array}{c}\text { Onset < } 15 \text { yo; } \\
1975 \text { - } 1976\end{array}$ & 236 & 1,241 & 24 & 60 & 10 & 52 & $\begin{array}{l}\text { - Maternal diabetes } \\
\text { - Maternal age } \\
\text { - Parity } \\
\text { - Gestational age } \\
\text { - Birthweight } \\
\text { - Social class }\end{array}$ \\
\hline $\begin{array}{l}\text { McKinney, et al, } \\
\text { UK (Yorkshire), } \\
1997 \text { [35] }\end{array}$ & $\mathrm{C}-\mathrm{C}$ & $\begin{array}{l}\text { Regional Diabetes } \\
\text { registry }\end{array}$ & $\begin{array}{c}\text { Onset < } 16 \text { yo; } \\
1993 \text { - } 1994\end{array}$ & 162 & 290 & 16 & 15 & 18 & 20 & - \\
\hline $\begin{array}{l}\text { Algert, et al, } \\
\text { Australia, } 2009 \\
\text { [44] }\end{array}$ & Cohort & Hospitalization & 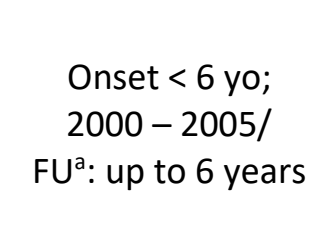 & 190 & 377,078 & 46 & 69,485 & 36 & 55,205 & $\begin{array}{l}\text { - Maternal diabetes } \\
\text { - Preeclampsia } \\
\text { - SGA (<10th centile) } \\
\text { - LGA (>90th centile) } \\
\text { - Preterm birth }\end{array}$ \\
\hline $\begin{array}{l}\text { Robertson and } \\
\text { Harrild, UK }\end{array}$ & $\mathrm{C}-\mathrm{C}$ & $\begin{array}{c}\text { Regional Diabetes } \\
\text { registry }\end{array}$ & $\begin{array}{c}\text { Onset < } 15 \text { yo; } \\
1984 \text { - } 2002\end{array}$ & 308 & 940 & 24 & 53 & 29 & 90 & - \\
\hline
\end{tabular}




\begin{tabular}{|c|c|c|c|c|c|c|c|c|c|c|}
\hline $\begin{array}{l}\text { (Grampian, } \\
\text { Scotland), } 2010 \\
{[32]}\end{array}$ & & $\begin{array}{c}\text { (Scottish Study } \\
\text { Group for the Care } \\
\text { of Diabetes in the } \\
\text { Young) }\end{array}$ & & & & & & & & \\
\hline $\begin{array}{l}\text { Black, et al (1), } \\
\text { UK, (Scotland) } \\
2015[56]\end{array}$ & Cohort & $\begin{array}{l}\text { Regional Diabetes } \\
\text { registry } \\
\text { (Scottish Care } \\
\text { Information } \\
\text { Diabetes } \\
\text { Collaboration - SCl } \\
\text { DC) }\end{array}$ & 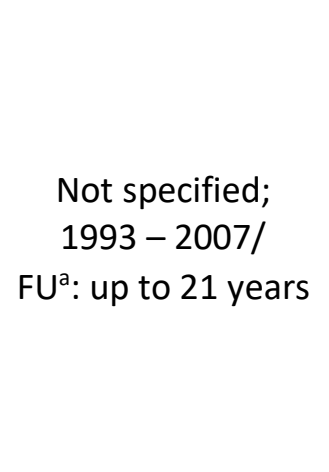 & 1,260 & 251,657 & 82 & 12,273 & 250 & 55,765 & $\begin{array}{l}\text { - Maternal age } \\
\text { - Gestation at birth } \\
\text { - Carstairs deprivation } \\
\text { score } \\
\text { - Maternal smoking } \\
\text { - Birthweight } \\
\text { - Year of delivery } \\
\text { - Infant gender } \\
\text { - Breastfeeding at } 6 \\
\text { weeks }\end{array}$ \\
\hline
\end{tabular}




\begin{tabular}{|c|c|c|c|c|c|c|c|c|c|c|}
\hline & & & & & & & & & & $\begin{array}{c}\text { - Maternal Type } 1 \\
\text { Diabetes (T1D) }\end{array}$ \\
\hline $\begin{array}{l}\text { Clausen, et al, } \\
\text { Denmark, } 2015 \\
{[57]}\end{array}$ & Cohort & National registry & $\begin{array}{c}\text { Onset < } 15 \text { yo; } \\
1982-2010 / \\
\text { FU }^{a} \text { : up to } 15 \text { years }\end{array}$ & 3,762 & $1,493,850$ & 302 & 122,487 & 336 & 139,599 & $\begin{array}{l}\text { - Year of birth } \\
\text { - Parental age at } \\
\text { childbirth } \\
\text { - Parental education } \\
\text { level } \\
\text { - Parental T1D } \\
\text { - First or higher birth } \\
\text { order } \\
\text { - Gestational age } \\
\text { - } \text { Birth weight }^{\mathrm{c}}\end{array}$ \\
\hline $\begin{array}{l}\text { Samuelsson, et } \\
\text { al, Sweden, } \\
2015[34]\end{array}$ & $\mathrm{C}-\mathrm{C}$ & $\begin{array}{l}\text { National Diabetes } \\
\text { study registry } \\
\text { (Swedish } \\
\text { paediatric diabetes } \\
\text { quality register - } \\
\text { SWEDIABKIDS) }\end{array}$ & $\begin{array}{c}\text { Onset < } 19 \text { yo; } \\
1984-2012\end{array}$ & 7,999 & 32,530 & 924 & 3,720 & 453 & 1,254 & Maternal diabetes \\
\hline
\end{tabular}


- Maternal T1D

${ }^{a}$ Follow-up.

${ }^{\mathrm{b}}$ Adjustment for these additional variables to the reported risk estimates did not change results.

${ }^{c}$ Restricting analyses to term births (>37 weeks gestation) or birth weight $>2500 \mathrm{~g}$ did not change results. 
Table 2. Crude OR and heterogeneity of all $C S^{\mathrm{a}}$ compared to $V D^{\mathrm{a}}$, elective $C S^{a}$ compared to $V D^{a}$, and non-elective $C S^{\mathrm{a}}$ compared to $V D^{\mathrm{a}}$.

\begin{tabular}{|c|c|c|c|c|c|c|c|}
\hline \multirow[b]{2}{*}{$\begin{array}{c}\text { Included } \\
\text { studies }\end{array}$} & & \multicolumn{2}{|c|}{$\begin{array}{c}\text { All } C S^{\mathrm{a}} \text { compared to } V^{\mathrm{a}} \\
\text { OR }(95 \% \mathrm{Cl})\end{array}$} & \multicolumn{2}{|c|}{$\begin{array}{l}\text { Elective } C^{\mathrm{a}} \text { compared to } \mathrm{VD}^{\mathrm{a}} \\
\text { OR }(95 \% \mathrm{Cl})\end{array}$} & \multicolumn{2}{|c|}{$\begin{array}{l}\text { Non-Elective } C^{\mathrm{a}} \\
\text { compared to } \mathrm{VD}^{\mathrm{a}} \\
\text { OR }(95 \% \mathrm{Cl})\end{array}$} \\
\hline & & Random & Heterogeneity & Random & Heterogeneity & Random & Heterogeneity \\
\hline \multirow[t]{2}{*}{$\begin{array}{l}\text { Cardwell, et al } \\
\text { [4] }\end{array}$} & Crude & $\begin{array}{c}1.23 \\
(1.15-1.32)\end{array}$ & $\begin{array}{l}I^{2}=0 \% \\
p=0.54\end{array}$ & NA & NA & NA & NA \\
\hline & Adjusted & $\begin{array}{c}1.19 \\
(1.04-1.36)^{b}\end{array}$ & $\begin{array}{c}1^{2}=0 \% \\
p=0.69\end{array}$ & NA & NA & NA & NA \\
\hline $\begin{array}{l}\text { Cardwell, et al } \\
{[4]+7 \text { studies }} \\
(\mathrm{N}=27)\end{array}$ & Crude $^{c}$ & $\begin{array}{c}1.12 \\
(1.05-1.20)\end{array}$ & $\begin{aligned} I^{2} & =49.8 \% \\
p & =0.002\end{aligned}$ & NA & NA & NA & NA \\
\hline 9 studies & Crude & $\begin{array}{c}1.06 \\
(0.98-1.15)\end{array}$ & $\begin{aligned} I^{2} & =68.1 \% \\
p & =0.002\end{aligned}$ & $\begin{array}{c}1.12 \\
(1.00-1.24)\end{array}$ & $\begin{aligned} I^{2} & =64.4 \% \\
p & =0.004\end{aligned}$ & $\begin{array}{c}1.05 \\
(0.89-1.24)\end{array}$ & $\begin{array}{c}\mathrm{I}^{2}=85.4 \% \\
\mathrm{p}<0.01\end{array}$ \\
\hline 7 studies $^{d}$ & Adjusted $^{e}$ & NA & & $\begin{array}{c}1.09 \\
(0.97-1.22)\end{array}$ & $\begin{array}{c}\mathrm{I}^{2}=72.7 \% \\
\mathrm{p}<0.01\end{array}$ & $\begin{array}{c}1.04 \\
(0.94-1.14)\end{array}$ & $\begin{array}{c}\mathrm{I}^{2}=51.9 \% \\
\mathrm{p}=0.05\end{array}$ \\
\hline
\end{tabular}

${ }^{\mathrm{a}} \mathrm{CS}=$ Caesarean section, $\mathrm{VD}=$ Vaginal delivery,

${ }^{\mathrm{b}}$ Adjusted for birthweight, gestational age, maternal age, birth order, breastfeeding, and maternal diabetes.

${ }^{\mathrm{c}}$ Adjusted estimates were not available.

${ }^{\mathrm{d}}$ Adjusted estimates from McKinney, et al and Robertson and Harrild, et al studies were not available.

${ }^{\mathrm{e}}$ Adjustments in each study according to the variables listed in the study characteristics (Table 1). 
Figure 1 Crude OR estimates of elective (upper) and non-elective (lower) Caesarean Section (CS; N - Total) risk on offspring Type 1 Diabetes (T1D) compared to vaginal delivery (VD; $\mathrm{N}$ - Total).

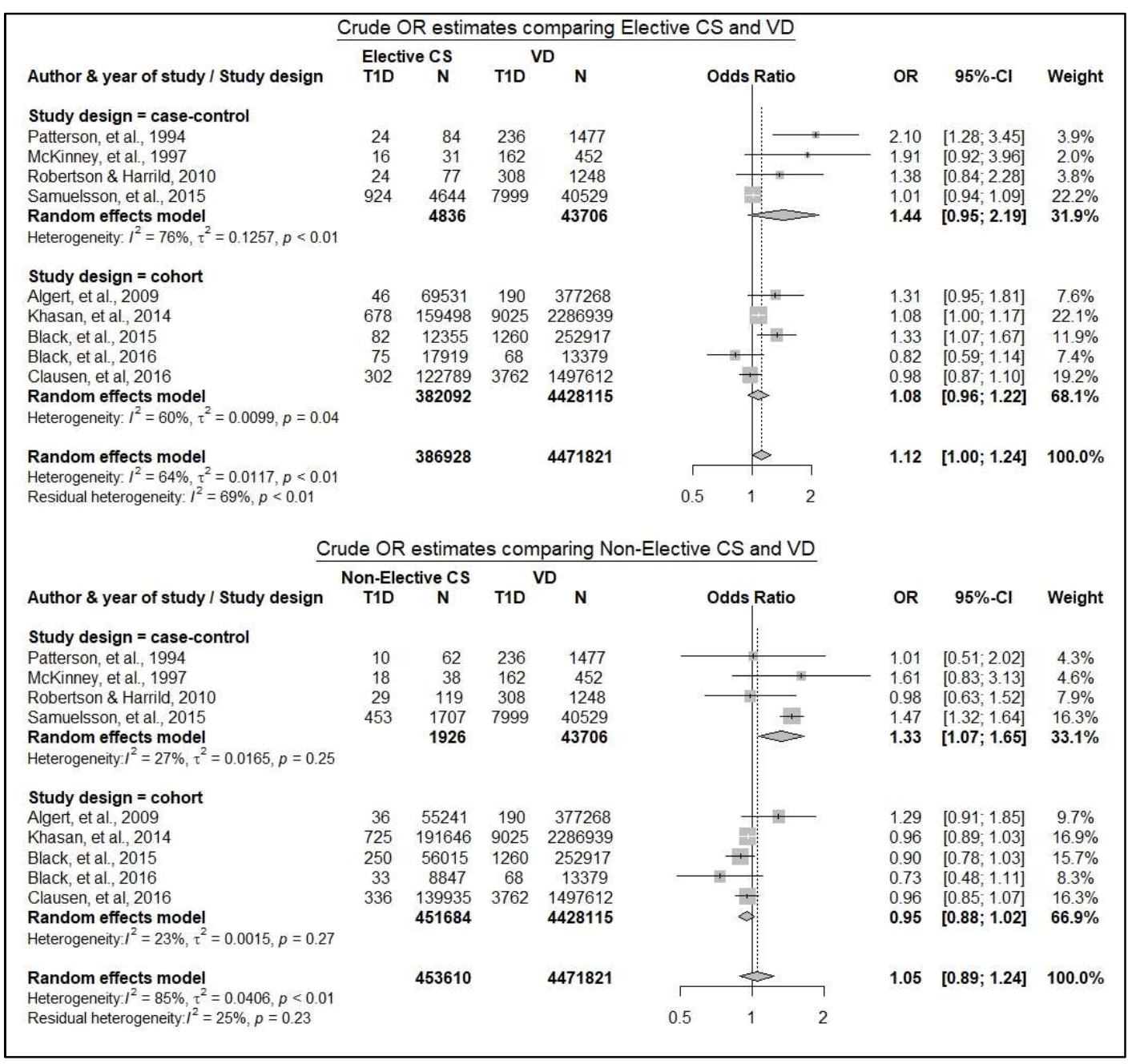


Figure 2 Summary adjusted OR (aOR) of elective (upper) or non-elective (lower) Caesarean section (CS; $\mathrm{N}$ - Total) on offspring Type 1 Diabetes (T1D) compared to vaginal delivery (VD; $\mathrm{N}$ - Total).

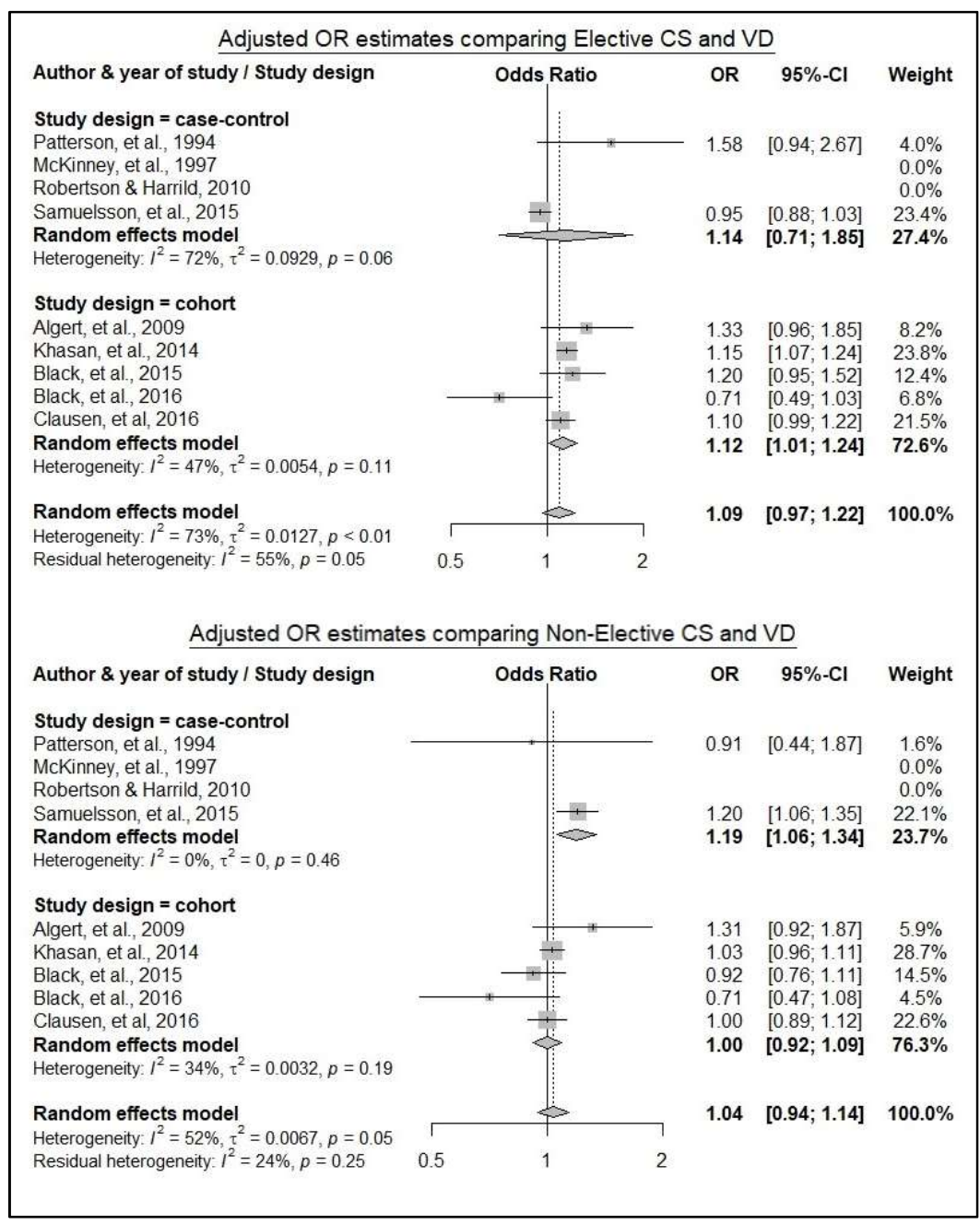

